\title{
A Complex Case of Adalimumab Induced Pleuropericarditis in a Patient with Underlying Ulcerative Colitis
}

\author{
Abbasi $\mathrm{A}^{1^{*}}$, Day $\mathrm{S}^{1}$, Subahani $\mathrm{M}^{2}$, Townson $\mathrm{G}^{1}$ \\ ${ }^{1}$ The Shrewsbury and Telford Hospital NHS Trust, England, United Kingdom \\ ${ }^{2}$ Nottingham Digestive Disease Biomedical Research Centre, University of Nottingham, England, United Kingdom
}

Corresponding Author: Abdullah Abbasi ${ }^{\text {ORCID iD }}$

Address: The Shrewsbury and Telford Hospital NHS Trust, England, United Kingdom.

Received date: 02 December 2020; Accepted date: 26 December 2020; Published date: 02 January 2021

Citation: Abbasi A, Day S, Subahani M, Townson G. A Complex Case of Adalimumab Induced Pleuropericarditis in a Patient with Underlying Ulcerative Colitis. Asp Biomed Clin Case Rep. 2021 Jan 02;4(1):16-21.

Copyright (C) 2021 Abbasi A, Day S, Subahani M, Townson G. This is an open-access article distributed under the Creative Commons Attribution License, which permits unrestricted use, distribution, and reproduction in any medium provided the original work is properly cited.

\begin{abstract}
Introduction: Adalimumab is an anti-tumour necrosis factor (anti-TNF) monoclonal antibody and an important part of the treatment regime for autoimmune conditions including inflammatory bowel disease. We present a case of adalimumab induced pleuropericarditis and discuss the diagnosis challenges we faced.

Case History: A 22-year-old male presented to the emergency department with 3 days history of headache, malaise, fever and right-sided chest pain. He was diagnosed with ulcerative colitis 8 months ago but failed to respond to mesalazine, requiring high dose steroids to induce disease remission. His mesalazine was stopped after 4 months and he was initiated on adalimumab 2 months prior to the current presentation. At presentation, he had a temperature of $38.7{ }^{\circ} \mathrm{C}\left(101.6{ }^{\circ} \mathrm{F}\right)$ but no other physical signs. His inflammatory markers were raised, and the chest x-ray was clear. He was started on empirical intravenous antibiotics on suspicion of the underlying infective process. On day 4 the patient developed a new pleural rub and crepitations on both lung bases. An urgent echocardiogram and computed tomography scan of the thorax abdomen and pelvis revealed pleural effusion and a $1.8 \mathrm{~cm}$ diameter pericardial effusion. Extensive investigation including virology screen, autoimmune screen and pleural fluid analysis were normal.

Diagnosis, Management and Outcome: This case was discussed in a multidisciplinary meeting. A diagnosis of pleuropericarditis secondary to adalimumab was made. Adalimumab and antibiotics were stopped, and he was started on a course of oral steroids. The patient responded well to the treatment and his symptoms resolved.

Conclusion: Rare drug toxicity should be part of differential diagnosis, especially in young patients with unusual presentation. An early multidisciplinary approach is crucial for a positive outcome. The patient should be actively involved in decision making to improve long term outcome.
\end{abstract}

\section{Keywords}

Ulcerative Colitis, Inflammatory Bowel Disease, Adalimumab, Pleuropericarditis

\section{Abbreviations}

IBD: Inflammatory Bowel Disease; UC: Ulcerative Colitis; CT: Computerized Tomography; TNF: Tumour Necrosis Factor 


\section{Introduction}

Anti-tumor necrosis factor (anti-TNF) monoclonal antibodies are the mainstay of treatment for a number of inflammatory and autoimmune conditions including ulcerative colitis, Crohn's disease rheumatoid arthritis, psoriasis, and ankylosing spondylitis. Adalimumab is one of the commonly used ani-TNF medication in inflammatory bowel disease both as induction and maintenance of remission therapy $[1,2]$.

Pleuropericarditis is a multifactorial inflammatory condition of the pleura and pericardium. The common causes include infection, malignancy, autoimmune conditions like inflammatory bowel disease, medications including (methotrexate, mesalazine, tretinoin, tryptophan), connective tissue, and metabolic disorders [3-6].

Adalimumab generally has a very good safety profile in patients with ulcerative colitis [7]. A recent review of VigiBase, the largest global database for reporting drug adverse reaction showed that pleuropericarditis secondary to anti-TNF is an extremely rare occurrence with only 94 reported cases out of 1175934 all cases on anti-TNF and for adalimumab 16/486,470. In 16 cases of adalimumab induced pleuropericarditis, up to half were due to underlying infection, over a quarter due to autoimmune etiology and a quarter had another drug contributing [1].

We aim to present a case of adalimumab induced pleuropericarditis, discuss the diagnostic challenges we experienced, and highlight the importance of a multidisciplinary approach in the management of complex cases.

\section{Case History}

A 22-year-old male presented to the emergency department with 3 days history of headache, malaise, fever, and right-sided chest pain. He had a past medical history of ulcerative colitis (UC) diagnosed 8 months ago after an index presentation to gastroenterology outpatient with a 6-month history of rectal bleeding and markedly raised fecal calprotectin of $800 \mathrm{ug} / \mathrm{g}$ (Normal $<100 \mathrm{ug} / \mathrm{g}$ ). He was initially started on mesalazine but continued to have ongoing diarrhea. Baseline colonoscopy showed mild-pancolitis on histology. He had a flare-up of UC 4 months after diagnosis requiring a course of oral steroids. Subsequently, his steroids were weaned off, mesalazine was stopped and after multidisciplinary team discussion, he was offered biologic treatment with infliximab or adalimumab. After reading information on both drugs, the patient chose adalimumab. He was started on adalimumab 2 months prior to his current presentation. At present, he was on the adalimumab maintenance dose of $40 \mathrm{mg}$ once every 2 weeks and his UC was under clinical remission. The patient was on no other medication and his family history was unremarkable.

On examination, he had a temperature of $38.7{ }^{\circ} \mathrm{C}$ $\left(101.6^{\circ} \mathrm{F}\right)$ but looked well in himself otherwise and had no other symptoms. The rest of his vital signs were within the normal range, his chest was clear, his heart sounds were normal, and he had no signs of meningeal irritations and no focal neurological signs either.

\section{Differential Diagnosis, Investigations, and Management}

In the context of the patient's history and presentation, a differential diagnosis of pneumonia and viral infection was considered.

The day one investigation (Table-1) showed a neutrophil count of $11.8 \times 10^{\wedge} 9 / \mathrm{L}$, c-reactive protein (CRP) of $80 \mathrm{mg} / \mathrm{L}$, and an unremarkable chest $\mathrm{x}$-ray. In view of raised inflammatory markers and the patient being on immunosuppression treatment, he was started on broad-spectrum intravenous (IV) antibiotics. Over the next 3 days despite being on regular IV antibiotics the patient continued to have a temperature as high as $39.6{ }^{\circ} \mathrm{C}\left(103.2{ }^{\circ} \mathrm{F}\right)$ and his inflammatory markers continued to rise (Table-1). On day 4 of his admission patient developed a new pleural rub and bibasal crepitations on examination. An urgent echocardiogram (Fig-1) and computed tomography scan (Fig-2) of the thorax abdomen and pelvis were organized which revealed pleural effusion and a $1.8 \mathrm{~cm}$ diameter pericardial effusion. A diagnostic pleural fluid tap polymerase chain reaction (PCR) was negative for influenza $\mathrm{A}$ and $\mathrm{B}$, parainfluenza virus, adenovirus, rhinovirus, human metapneumovirus, cytomegalovirus (CMV), and Epstein-Barr virus (EBV). Pleural fluids 
Citation: Abbasi A, Day S, Subahani M, Townson G. A Complex Case of Adalimumab Induced Pleuropericarditis in a Patient with Underlying Ulcerative Colitis. Asp Biomed Clin Case Rep. 2021 Jan o2;4(1):16-21.

culture, T spot test for tuberculosis (TB) and CMV and EBV blood test, as well as autoimmune screen including $\mathrm{p}$-ANCA and c-ANCA, MPO and PR3 antibodies, were also negative (Table-1). On day 6 of his admission, a multi-disciplinary meeting involving gastroenterology respiratory, and cardiology teams was held. His presenting history and investigations were reviewed. It was concluded that the most likely had adalimumab induced pleuropericarditis. Even though non-steroidal anti-inflammatory drugs (NSAIDs) could be considered as the first line of treatment, they could trigger a flare-up of ulcerative colitis. After discussing all options with the patients, it was recommended to stop antibiotics and, adalimumab, as well as to start oral steroids. Oral prednisolone was started (40mg once/day). Patient symptoms quickly responded to treatment and his inflammatory markers normalized. He was discharged home a week later with a plan to follow up in a gastroenterology clinic.

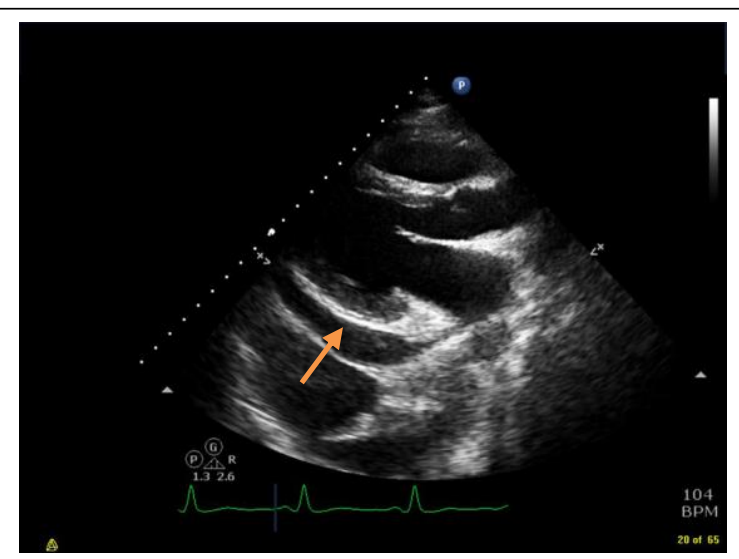

Fig-1:

Trans-thoracic Echocardiogram showing Pericardial effusion (as indicated by arrow sign)

Table-1: Investigation results (CRP-C reactive protein, ANCA-anti-nuclear cytoplasmic antibody, MPO-myeloperoxidases, EBV-Epstein-Barr virus, CMV-cytomegalovirus, T-spot-tuberculosis test)

\begin{tabular}{|c|c|c|c|c|c|}
\hline Normal & Day 1 & Day 3 & Day 5 & $\begin{array}{l}\text { 24-hour Post } \\
\text { steroids }\end{array}$ & Reference range \\
\hline Haemoglobin & 132 & 128 & 124 & 128 & $130-170 \mathrm{~g} / \mathrm{L}$ \\
\hline White cell count & 11.8 & 11.3 & 13.7 & $9 \cdot 7$ & $4 \times 10^{\wedge} 9 / \mathrm{L}-11 \times 10^{\wedge} 9 / \mathrm{L}$ \\
\hline Platelets & 453 & 458 & 503 & 497 & $150 \times 10^{\wedge} 9 / \mathrm{L}-450 \times 10^{\wedge} 9 / \mathrm{L}$ \\
\hline CRP & 80 & 193 & 327 & 61 & $(<4 \mathrm{mg} / \mathrm{L}$ \\
\hline Urea & 6.8 & 7.4 & 7.9 & $5 \cdot 9$ & $2.5 \mathrm{mmol} / \mathrm{L}-7.0 \mathrm{mmol} / \mathrm{L}$ \\
\hline Creatinine & 96 & 87 & 113 & 87 & $74 \mu \mathrm{mol} / \mathrm{L}-107 \mu \mathrm{mol} / \mathrm{L}$ \\
\hline Albumin & 41 & 37 & 37 & 43 & $35-50 \mathrm{og} / \mathrm{L}$ \\
\hline Blood culture & Negative & Negative & Negative & & \\
\hline Urine culture & Negative & Negative & Negative & & \\
\hline T Spot & & & Negative & & \\
\hline p-ANCA and c ANCA & & & Negative & & \\
\hline MPO & & & Negative & & \\
\hline Influenza A/B & & Negative & & & \\
\hline CMV & & & Negative & & \\
\hline EBV & & & Negative & & \\
\hline
\end{tabular}


Citation: Abbasi A, Day S, Subahani M, Townson G. A Complex Case of Adalimumab Induced Pleuropericarditis in a Patient with Underlying Ulcerative Colitis. Asp Biomed Clin Case Rep. 2021 Jan o2;4(1):16-21.

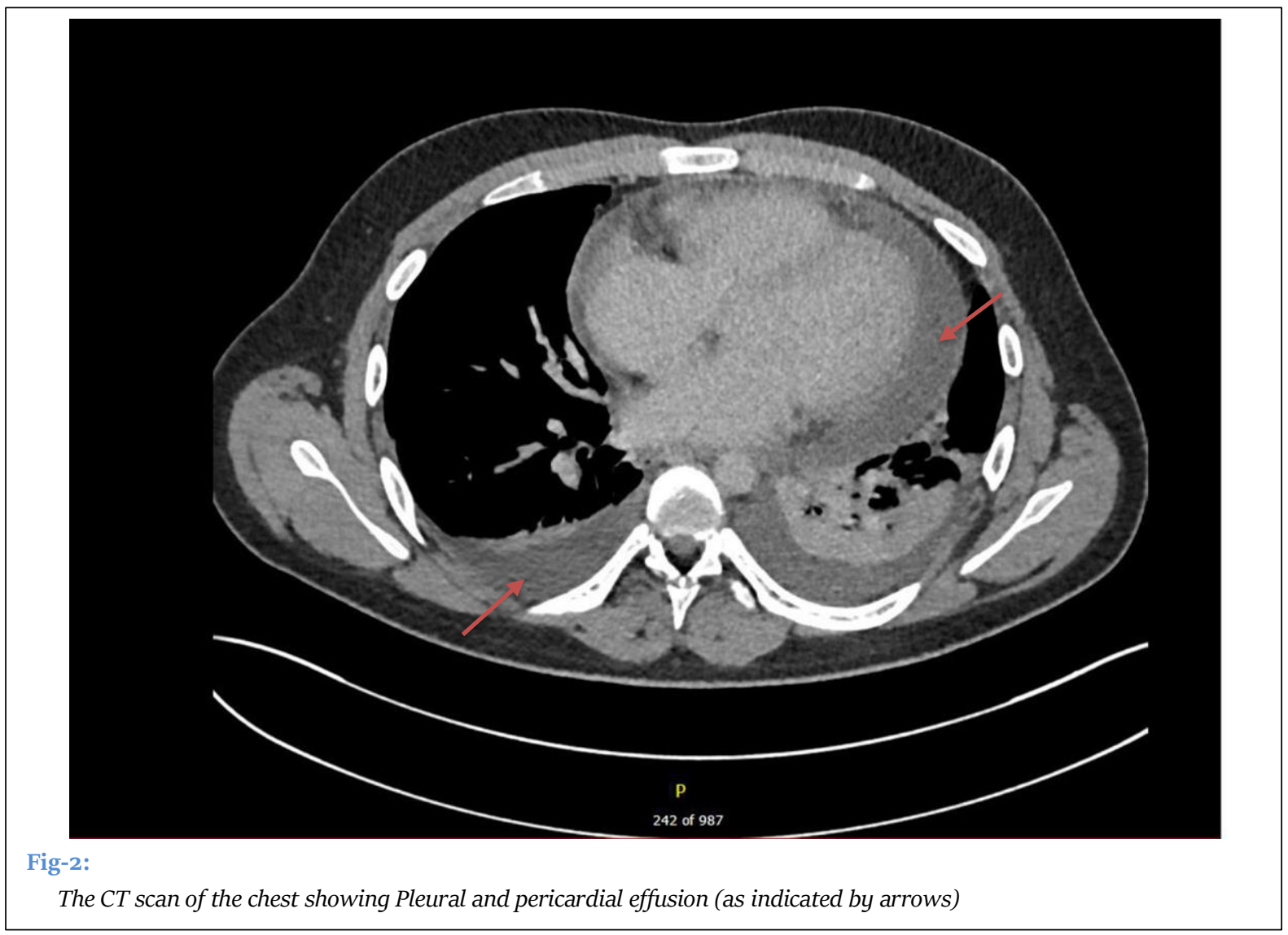

\section{Outcome and Follow up}

He was followed up in the gastroenterology clinic after 4 weeks. All his symptoms had resolved, and steroids were weaned off. He had since remained well and is under follow-up with the gastroenterology team. He is planned to be started on Vedolizumab or Tofacitinib to manage his ulcerative colitis in case of any future flares. He has no clinical symptoms currently but his last fecal calprotectin was $278 \mathrm{ug} / \mathrm{g}$ (Normal <100 ug/g). He didn't attend his appointment for flexi-sigmoidoscopy due to COVID 19 concerns and is due for another telephone consultant in 2 months' time.

\section{Discussion}

This case was challenging on various fronts. Being on biologics, the infection was a top differential initially, and therefore, the patient was started on broad-spectrum antibiotics. Other differentials were only considered once the patient did not respond to antibiotics, had a continuous high temperature and inflammatory markers were going up. In hindsight, a normal examination of the initial presentation should have provoked a wide differential diagnosis. Patient with pleuropericarditis can have other subtle clinical signs on the presentation like pericardial rub or crackles on lung bases.

There is no clear pathophysiology documented to explain these side effects. Case reports have suggested links with infection, humoral antibody response, hypersensitivity reactions, and direct cardiotoxicity, but no clear link is established in our case [8]. Our patient had symptoms after his loading dose of Adalimumab but had no GI symptoms and an extensive virology screen was negative. There was no evidence of infection and the extensive autoimmune screen was negative as well. All these are suggestive of drug-induced reactions. Biologics have an everincreasing role in the management of inflammatory bowel disease [8]. This makes it key for physicians and gastroenterologists to be aware of common as well as rare side effects of these drugs. Moreover, biologic-induced side effects like pleuropericarditis should be high on differential diagnosis with patients with unusual presentation. 
Our case was challenging in the management aspects as well. Whilst pleuropericarditis can usually be successfully managed with NSAIDs, this was not our choice, as he had UC. NSAIDs have adverse effects in UC, causing gastrointestinal mucosal damage on already inflamed and damaged mucosa [9,10]. Steroids were an alternative treatment option. Despite all investigations, at the time there was always a possibility of hidden underlying infection. Steroids had the potential of making it worse. This issue was resolved by involving various specialties and having informed risk and benefit discussion with the patient.

\section{Conclusion}

In summary, our patient with a background of UC on adalimumab presented with a history of fever and chest pain. He was subsequently diagnosed with pleuropericarditis. Extensive investigations did not reveal a cause. This was diagnosed as a drug-induced reaction and responded well to steroids.

\section{Learning Points}

- Consider medication side effects in patients on biologic treatment presenting with febrile illness.

- A multi-disciplinary approach represents the key in deciding on management in complex patients.

Patients should be involved in all decision making. Regarding complexity in patients care, it appears crucial to discuss with patient all treatment options as a team with members from all specialities.

\section{Authors Contribution}

Abdullah Abbasi: Developing Case report Concept and design, Consent, Data collection, Literature search, Critical analysis, Drafting Manuscript, Revision, and writing up final Manuscript.

Sara Day: Literature search, drafting manuscript, revision of Manuscript.

Mohsan Subhani: Literature search, revision, and writing up the final manuscript.

Gill Townson: Revision of manuscript, senior author

\section{Acknowledgment}

No Author received any financial or material support.

\section{Ethics}

Written informed consent was obtained from the patient.

\section{Conflict of Interests}

All authors have read and approved the final version of the manuscript. The authors have no conflicts of interest to declare.

\section{References}

[1] Feuerstein JD, Isaacs KL, Schneider Y, Siddique SM, Falck-Ytter Y, Singh S; AGA Institute Clinical Guidelines Committee. AGA Clinical Practice Guidelines on the Management of Moderate to Severe Ulcerative Colitis. Gastroenterology. 2020 Apr;158(5):1450-61. [PMID: 31945371]

[2] Lamb CA, Kennedy NA, Raine T, Hendy PA, Smith PJ, Limdi JK, Hayee B, Lomer MCE, Parkes GC, Selinger C, Barrett KJ, Davies RJ, Bennett C, Gittens S, Dunlop MG, Faiz O, Fraser A, Garrick V, Johnston PD, Parkes M, Sanderson J, Terry H; IBD guidelines eDelphi consensus group, Gaya DR, Iqbal TH, Taylor SA, Smith M, Brookes M, Hansen R, Hawthorne AB. British Society of Gastroenterology consensus guidelines on the management of inflammatory bowel disease in adults. Gut. 2019 Dec;68(Suppl 3):s1-s106. [PMID: 31562236]

[3] Massart A, Hunt DP. Pulmonary Manifestations of Inflammatory Bowel Disease. Am J Med. 2020 Jan;133(1):39-43. [PMID: 31398306]

[4] O'Morain N, Kumar L, O'Carroll-Lolait C, Alakkari A, Ryan B. Infliximab Induced Cardiac Tamponade. Ir Med J. 2019 Mar 14;3(112):902. [PMID: 31124350]

[5] Harbord M, Annese V, Vavricka SR, Allez M, Barreiro-de Acosta M, Boberg KM, Burisch J, De Vos M, De Vries AM, Dick AD, Juillerat P, Karlsen TH, Koutroubakis I, Lakatos PL, Orchard T, Papay P, Raine T, Reinshagen M, Thaci D, Tilg H, Carbonnel F; European Crohn's and Colitis Organisation. The First European Evidence-based Consensus on Extraintestinal Manifestations in Inflammatory Bowel Disease. J Crohns Colitis. 2016 Mar;10(3):239-54. [PMID: 26614685]

[6] Naseer M, Kulairi Z, Kam M. Cardiac Tamponade as a Presenting Manifestation of Infliximab-Induced Lupus in Patient Treated for Crohn's Disease. ACG Case Rep J. 2017 Jan 4;4:e1. [PMID: 28138445] 
Citation: Abbasi A, Day S, Subahani M, Townson G. A Complex Case of Adalimumab Induced Pleuropericarditis in a Patient with Underlying Ulcerative Colitis. Asp Biomed Clin Case Rep. 2021 Jan o2;4(1):16-21.

[7] Bálint A, Farkas K, Palatka K, Lakner L, Miheller P, Rácz I, Hegede G, Vincze Á, Horváth G, Szabó A, Nagy

F, Szepes Z, Gábor Z, Zsigmond F, Zsóri Á, Juhász M, Csontos Á, Szű́cs M, Bor R, Milassin Á, Rutka M, Molnár T. Efficacy and Safety of Adalimumab in Ulcerative Colitis Refractory to Conventional Therapy in Routine Clinical Practice. J Crohns Colitis. 2016 Jan;10(1):26-30. [PMID: 26392413]

[8] Rawla P, Sunkara T, Raj JP. Role of biologics and biosimilars in inflammatory bowel disease: current trends and future perspectives. J Inflamm Res. 2018
May 16;11:215-26. [PMID: 29844695]

[9] Klein A, Eliakim R. Non Steroidal AntiInflammatory Drugs and Inflammatory Bowel Disease. Pharmaceuticals (Basel). 2010 Apr 12;3(4):1084-92. [PMID: 27713289]

[10] Long MD, Kappelman MD, Martin CF, Chen W, Anton K, Sandler RS. Role of Nonsteroidal AntiInflammatory Drugs in Exacerbations of Inflammatory Bowel Disease. J Clin Gastroenterol. 2016 Feb;5O(2):152-56. [PMID: 26485106] 